\title{
CUESTIONES CONSTITUCIONALES DE LA RESPONSABILIDAD DE LOS MEDIOS DE COMUNICACIÓN POR PUBLICIDAD ENGAÑOSA
}

\author{
Jorge Ricardo Palomares G. LL. M.*
}

Fecha de recepción: 12 de abril de 2012

Fecha de evaluación: 13 de abril 2012

Fecha de aprobación: 30 de julio de 2012

\section{Resumen}

El presente artículo pretende establecer la relación existente entre la libertad de expresión, como derecho amplio, y el deber de transmitir publicidad clara veraz, traducida en la nueva figura creada por la ley 1480 de 2011, la cual responsabiliza a los medios de comunicación por la emisión de publicidad engañosa.

\section{Palabras Clave}

Estatuto del consumidor, publicidad engañosa, libertad de expresión, libertad de información, libertad de medios de comunicación.

\section{Abstract}

This article aims to identify the relationship between freedom of expression, as broad right and the duty to transmit clear truthful advertising, translated in the new figure created by Act 1480 of 2011, which blamed the media for the issue of misleading advertising.

\footnotetext{
* Abogado, Legum Magister de la Universität Konstanz, Doctorando en Derecho de la Universität Konstanz, Docente-Tutor de la Maestría en Derecho Público y de la Maestría en Gobernabilidad y Democracia de la Universidad Santo Tomás-Bogotá, Investigador del proyecto "Globalización del Derecho Privado", Universidad Santo Tomás Bogotá - GIZ.
} 


\section{Key words}

Consumer status, false advertising, freedom of speech, freedom of information, freedom of media.

\section{Introducción}

El derecho del consumidor es nuevamente, un tema de especial interés en el ámbito colombiano, pues en torno a él han surgido algunas situaciones interesantes, las cuales no sólo plantean cuestiones en la regulación consumidor-empresario, sino cuestiones en torno a la publicidad y a los derechos fundamentales. Así, en noviembre del año pasado, la Sala Civil de la Corte Suprema de Justicia, en sentencia del 1 de noviembre de 2011, estableció, fundándose en jurisprudencia emitida por el mismo Tribunal anteriormente, que la publicidad está subordinada no sólo al derecho constitucional colectivo que le asiste al consumidor en materia de control de calidad de bienes y servicios, sino que también le asiste, conforme al art. 20 inc. $1^{\circ}$ de la Constitución Política de Colombia, el derecho fundamental de estar informado, y ojala bien informado (Corte Suprema de Justicia, 2011: Setencia 029201/2011). Por otra parte, la Superintendencia de Industria y Comercio, mediante la Resolución 5985 de 2012, sancionó a una compañía estética, por publicitar uno de sus productos bajo la expresión "eterna juventud", aduciendo que los anunciantes -productor, proveedor o persona encargada- no pueden publicitar sus productos omitiendo lo autorizado por el registro INVIMA, ni que se le puede ofrecer un producto a la comunidad, cuyas características no gozan de sustento científico alguno.

Otro tema, de especial interés en el derecho constitucional económico, ha sido la expedición de la ley 1480 de 2011, cuyo art. 30 inc. $2^{\circ}$ consagra que los medios de comunicación son responsables solidariamente por los perjuicios causados por la transmisión de publicidad engañosa. Dicha disposición ha sido demanda ante la Corte Constitucional, la cual deberá determinar si aquella constituye una violación o no a los derechos fundamentales de los medios de comunicación o si, por el contrario, es una norma constitucionalmente legítima, 
orientada a la protección de los derechos de los consumidores, consagrados especialmente en el art. 78 de la Constitución Política de Colombia. Por ello, el presente artículo tiene como objeto analizar la relación que tiene la libertad de expresión, como derecho fundamental amplio, con la obligación de los medios de comunicación de transmitir información clara y veraz, traducida en la responsabilidad solidaria de aquellos por la emisión de publicidad engañosa. Para ello, se revisará cómo se ha entendido el tema de la responsabilidad por publicidad engañosa en la legislación colombiana (I). Posteriormente, se analizará si la publicidad comercial está protegida por los derecho fundamentales y, en caso de estarlo cuáles son sus límites (II). Por último, se determinará si el derecho fundamental que cobija la publicidad engañosa cubre también a los medios de comunicación o si, por el contrario, está protegia por otro derecho fundamental y cuáles son los límites del mismo en materia de protección al consumidor en materia de información veraz (III).

\section{La responsabilidad de los medios de comunicación por publicidad engañosa en el Derecho colombiano}

A. La publicidad comercial y la publicidad engañosa

La publicidad, como parte del marketing (GARCÍA-UCEDA, 2008: 52), es una herramienta comunicativa (RODRíGUEZ C., 2004: 3) empleada por el productor, proveedor o anunciante de un producto y cuya finalidad es la de persuadir (SCRETI, 2012: 6) al consumidor para que se incline por el producto ofrecido. Para ello, el productor, proveedor o anunciante del producto deben lograr transmitir, a través de un discurso que puede ser gráfico -visual- o auditivo, un conjunto de características relacionadas con el producto, su precio, su forma de distribución, entre otros (RODRIGUEZ C., 2004: 5), especialmente, debe informar al consumidor sobre la calidad del producto, sus ventajas y sus formas de uso.

Dicha acción persuasiva por parte del productor, proveedor o anunciante de un producto ha sido considerada legítima desde el Derecho (ISLER S., 2010: 128), pues, como lo ha sostenido la Corte Constitucional (2010: Sentencia C- 
830/2010), la publicidad expresa el ejercicio de las libertades económicas y la define como la propagación de noticias o anuncios de carácter comercial o profesional con el fin de atraer adeptos, compradores, espectadores 0 usuarios, o crear simpatizantes a través de cualquier medio de divulgación (Corte Constitucional, 2010: Sentencia C-830/2010). El Derecho colombiano, empero, no ha sido el único en reconocer la legitimidad de la publicidad. En el Derecho de la Unión Europea, por ejemplo, el art. 2 lit. a) de la Directiva 2006/114/CE reconoce la publicidad y la define como toda forma de comunicación realizada en el marco de una actividad comercial con el fin de promover el suministro de bienes o la prestación servicios, incluidos los bienes inmuebles, los derechos y las obligaciones. Asimismo, el art. 1 num. 4 de la ley de protección al consumidor de Chile reconoce la publicidad y la entiende como la comunicación que el proveedor dirige al público por cualquier medio idóneo al efecto, para informarlo y motivarlo a adquirir o contratar un bien o servicio (ISLER S., 2010: 127.).

Sin embargo, la publicidad comercial no puede ser realizada de cualquier forma, pues, si bien el objetivo es convencer al consumidor para que opte por un producto, la misma debe respetar unos límites, los cuales están consagrados en normas de rango comunitario, constitucional y del derecho del consumidor. Por ejemplo, el Derecho de la Unión europea entiende en su Directiva 2006/114/CE que la realización de una publicidad inadecuada engañosa o comparativa- puede distorsionar la competencia en el seno del mercado interior y, a su vez, puede afectar la situación económica de los consumidores y empresarios. Asimismo, la Corte Suprema de Justicia colombiana (2001: Sentencia 6775/2001) sostuvo que la publicidad encuentra unos límites en el derecho del consumidor, a quien le asiste, entre otros, el derecho a estar bien informado, derecho que no sólo goza de un respaldo legal, sino que tiene un reconocimiento positivo en los arts. 20 y 78 de la Constitución Política de Colombia, donde de un lado se confiere rango constitucional al derecho a recibir información veraz y, de otro, se confiere a la ley la misión de controlar la información dada en la comercialización de los bienes y servicios ofrecidos y prestados a la comunidad (Corte Suprema de Justicia, 2001: Sentencia 6775/2001). En caso de no respetar los límites 
consagrados en el ordenamiento jurídico, la publicidad emitida tendría un carácter ilícita (ISLER S., 2010: 128) y sería necesario la acción del Estado, a fin de garantizar los derechos de los consumidores y de los demás empresarios.

Una de las expresiones de la publicidad ilícita (SUÁREZ V.; PÉREZ C., 2001: 26 s.) en el derecho de la protección del consumidor es la publicidad engañosa, la cual ha sido entendida como aquella que induce a error o a engaño (ISLER S., 2010: 129) y que puede llegar a transgredir la buena fe contractual (ISLER S., 2010: 129). En el Derecho de la Unión Europea, por ejemplo, el art. 2 lit. b) de la Directiva 2006/114/CE define la publicidad engañosa como toda publicidad que, de una manera cualquiera, incluida su presentación, induce a error o puede inducir a error a las personas que se dirige o afecta y que, debido a su carácter engañoso, puede afectar su comportamiento económico o que, por estas razones, perjudica o es capaz de perjudicar a un competidor (COHEN, 1980: 209).

Para el caso colombiano, es de cuestionarse si la normativa en materia de protección al consumidor ha consagrado reglas en torno a la prohibición o sanción a agentes del mercado por utilización de publicidad engañosa.

B. La publicidad engañosa a la luz del decreto 3466 de 1982

En el estatuto del consumidor de 1982 se consagraron normas sobre la publicidad emitida por el productor, el proveedor y el anunciante. Así el art. 14 inc. 1ํ del decreto 3466 de 1982 estableció que toda información que se dé al consumidor acerca de los componentes y propiedades de los bienes y servicios que se ofrezcan al público deberá ser veraz y suficiente. Igualmente, el art. 14 inc. $2^{\circ}$ del decreto 3466 de 1982 prohibió, sin utilizar el término de publicidad engañosa, las marcas, las leyendas y la propaganda comercial que no correspondan a la realidad, así como las que induzcan o puedan inducir a error respecto a la naturaleza, el origen, el modo de fabricación, los componentes, los usos, el volumen, el peso o medida, la forma de empleo, las características, 
las propiedades, la calidad, la idoneidad o la cantidad de los bienes o servicios ofrecidos.

La Superintendencia de Industria y Comercio, a través del num. 2.1.1 de la Circular 010 de 2001, utilizó el término de información engañosa y la entendió como la propaganda comercial, marca o leyenda de cualquier manera, incluida su presentación, induzca a error o pueda inducir a error a los consumidores o personas a las que se dirige o afecta y que, debido a su carácter engañoso, puede afectar el comportamiento económico. Por su parte, el art. 31 inc. $1^{\circ}$ del decreto 3466 de 1982 estableció que sólo son responsables por la publicidad o información engañosa, los productores por las marcas y leyendas que exhiban sus productos, así como por la propaganda comercial de los mismos, cuando su contenido no corresponde a la realidad o induzca a error. Este criterio se mantuvo hasta el 2011, año en el cual, fueron considerados otros agentes como sujetos responsables por publicidad engañosa.

C. La publicidad engañosa a la luz de la ley 1480 de 2011

A mediados de octubre de 2011, el Congreso de la República expidió la ley 1480 de 2011, por la cual se expide el nuevo estatuto del consumidor y se dictan otras disposiciones. El objetivo de esta nueva es, básicamente, darle una mayor coherencia y unidad a la normativa de protección del consumidor y orientarla bajo el art. 78 de la Constitución Política de 1991, el cual da un tratamiento preferencial al consumidor como agente económico débil en las relaciones económicas (Congreso de la República, 2010: 21). Para alcanzar dicho objetivo, la propuso varias novedades ( Congreso de la República, 2010: 23 ss.), entre ellas, la publicidad, la cual es de importancia para la los consumidores (Congreso de la República, 2010: 23) y requiere de la participación de todos los actores, especialmente de los anunciantes de publicidad (Congreso de la República, 2010: 23).

En este sentido, el art. 5 de la ley 1480 de 2011, cuya vigencia inicia el 12 de abril de 2012, incluyó, a diferencia del antiguo estatuto del consumidor, el concepto expreso de publicidad engañosa, entendida como aquella cuyo mensaje no corresponda a la realidad o sea insuficiente, de manera que 
induzca o pueda inducir a error, engaño o confusión. Asimismo, consagró el art. 30 inc. $1^{\circ}$ de la ley 1480 de 2011 que está prohibida la publicidad engañosa $y$, en caso de transmitirse, el anunciante -bien sea el productor, proveedor o una persona encargada por ellos para la publicidad del productoserá responsable por los perjuicios que cause la publicidad engañosa, conforme al art. 30 inc. $2^{\circ}$ de la ley 1480 de 2011. Sin embargo, esta ley amplía la responsabilidad por publicidad engañosa a otros sujetos. Así, el mismo art. 30 inc. $2^{\circ}$ de la ley 1480 de 2011 estableció que los medios de comunicación serán responsables solidariamente solo si se comprueba dolo o culpa grave.

Por medios de comunicación se entiende, conforme a la jurisprudencia de la Corte Constitucional, no sólo a la televisión, quien tiene un deber de control de contenidos conforme al art. 29 de la ley 182 de 1995, sino también a los medios de comunicación radial e impresa (Corte Constitucional, 2010: Sentencia C-830/2010). Sin embargo, su responsabilidad no similar a la del anunciante, quien ha diseñado y transmitido la publicidad, sino que sólo responde por una actuación dolosa o culposa. Por actuación dolosa se entiende, en el caso de publicidad engañosa, que el medio de comunicación conoce o es consciente de que la publicidad a ser transmitida no corresponde con la realidad o es insuficiente -induciendo o pudiendo inducir a error- $y$, sin embargo, autoriza la transmisión de la publicidad; en cambio, por actuación culposa se entiende que, si bien el medio de comunicación no tiene conocimiento 0 no es consciente de que la publicidad a ser emitida no corresponde a la realidad o es insuficiente, aquel no realizó los controles necesarios para corroborar la veracidad del contenido que va a ser transmitido.

Esta norma, si bien es novedosa en el ordenamiento jurídico colombiano, ha causado ciertas inquietudes. Ello se refleja en la demanda de constitucionalidad de la cual ha sido objeto el art. 30 inc. $2^{\circ}$ de la ley 1480 de 2011, pues se ha considerado que el mismo es una aparente violación al derecho fundamental a la libertad de expresión, pues los medios de comunicación, no son órganos de control sino medios de difusión de la información y, al imponerle una responsabilidad implicaría crearle una carga a los medios de comunicación de crear divisiones o departamentos de control 
especializados. Asimismo, imponerle una responsabilidad por la transmisión de publicidad engañosa constituiría una sanción excesiva, pues los medios de comunicación no tienen relación directa con la publicidad, ya que ella no participa con el diseño de la misma. Pero, para poder determinar si es inconstitucional dicha norma que sanciona con responsabilidad solidaria a los medios de comunicación por la transmisión de publicidad engañosa, es necesario determinar se está afectando un derecho fundamental o no. Para ello es necesario diferenciar dos situaciones. La primera es si la publicidad comercial está protegida por un derecho fundamental y, en caso afirmativo, quiénes son los sujetos protegidos. La segunda consiste en determinar si, en realidad, los medios de comunicación gozan de este derecho o si, por el contrario, están frente a otro derecho fundamental y, en caso de ser afirmativo, si el mismo puede ser restringido por una norma de responsabilidad solidaria.

\section{Protección constitucional de la publicidad comercial}

A. Generalidades del ámbito de protección constitucional de la libertad de expresión

El art. 20 inc. $1^{\circ}$ de la Constitución Política de 1991 consagra que se garantiza a toda persona la libertad de expresar y difundir su pensamiento y opiniones, la de informar y recibir información veraz e imparcial, y la de fundar medios masivos de comunicación.

Por toda persona se entiende, en principio, toda persona natural colombiana y, conforme al art. 100 inc. $1^{\circ}$ de la Constitución Política de 1991, a todos los extranjeros, quienes disfrutarán de los mismos derechos 'que se le conceden a los colombianos (Corte Constitucional, 2001: Sentencia C-1259/01). Es de cuestionarse, sin embargo, si las personas jurídicas gozan también de las garantías consagradas en el art. 20 inc. 1ํo de la Constitución Política de 1991. Para la Corte Constitucional, en principio, si bien las personas jurídicas no gozan de todos los derechos fundamentales que gozan las personas naturales (Corte Constitucional, 2010: Sentencia T-161/2010), son titulares de algunos derechos fundamentales que pueden ser objeto de protección por el juez 
constitucional en caso de darse las condiciones previstas en la Constitución y la Ley (Corte Constitucional, 2010: Sentencia T-161/2010). Asimismo, la Corte Constitucional ha sostenido que, en materia de fundar medios masivos de comunicación, de prestación de servicios públicos y de uso del espectro electromagnético, las personas jurídicas gozan de los mismos derechos que gozan las personas naturales (Corte Constitucional, 1998: Sentencia SU182/1998). Por tanto, el art. 20 inc. 1o de la Constitución Política de 1991 protege no sólo a las personas naturales nacionales, sino también a los extranjeros y las personas jurídicas.

Las personas protegidas por el art. 20 inc. $1^{\circ}$ de la Constitución Política de 1991 gozan de un derecho fundamental a la comunicación, el cual se concreta en tres derechos distintos. Para la Corte Constitucional, en el art. 20 inc. $1^{\circ}$ de la Constitución Política de 1991 se distingue entre la libertad de expresión, la libertad de información y la libertad de fundar medios masivos de comunicación (Corte Constitucional, 2007: Sentencia T-391/2007). La libertad de expresión, por una parte, se entiende, de acuerdo a la Corte Constitucional y a la luz del Bloque de Constitucionalidad, como la libertad de expresar y difundir el propio pensamiento, opiniones, informaciones e ideas, sin limitación de fronteras (Corte Constitucional, 2007: Sentencia T-391/2007). Asimismo, la libertad de expresión garantiza que dichas manifestaciones puedan ser difundidas por cualquier medio (PÉREZ E., 2004: 313), sea oral, escrito, impreso, artístico, simbólico, electrónico u otro de elección de quien se expresa (Corte Constitucional, 2007: Sentencia T-391/2007). Por otra parte, la libertad de expresión protege a toda persona, que ha manifestado una idea, pensamiento $\mathrm{u}$ otros, de ser molestado por lo expresado (Corte Constitucional, 2007: Sentencia T-391/2007). Es necesario aclarar, sin embargo, que no toda manifestación está protegida por el art. 20 inc. 1ํ de la Constitución Política de 1991. Las expresiones o manifestaciones que tengan un carácter injurioso (CÁRDENAS, 2010: 37), discriminatorio o que constituyen una calumnia, se encuentran excluidas del ámbito de protección de la libertad de expresión, pues las mismas constituyen, en el Derecho constitucional colombiano, en una violación directa de otros derechos fundamentales, tales como el libre desarrollo de la personalidad -art. 16 de la Constitución Política de 1991-, la 
prohibición de tratos discriminatorios -art. 13 inc. $1^{\circ}$ de la Constitución Política de 1991-, el derecho a la honra -art. 21 de la Constitución Política de 1991(YOUNES, 2011: 131), entre otros.

Es necesario diferenciar, a su vez, entre la libertad de expresión y la libertad de información pues, de acuerdo a la Corte Constitucional, pues mientras que éste se sólo pretende informar, es decir, enterar o dar noticias sobre un determinado evento (Corte Constitucional, 2004: Sentencia T-787/2004), aquella involucra todo tipo de declaración que tenga por objeto difundir un pensamiento, idea, opinión, etc. (Corte Constitucional, 2004: Sentencia T-787/2004). En este sentido, la libertad de información protege, en general, la comunicación de versiones sobre los hechos, eventos, acontecimientos, gobiernos, funcionarios, personas, grupos y general situaciones (Corte Constitucional, 2007: Sentencia T-391/2007), a fin de enterar a la sociedad sobre lo que está ocurriendo. La libertad de información, al mismo tiempo, debe ser visto, concretamente, en dos dimensiones. Desde una primera dimensión, orientada a la persona que transmite la información, el art. 20 inc. 1ํ de la Constitución Política de 1991 protege la libertad de buscar o investigar información sobre hechos, ideas y opiniones de toda índole (Corte Constitucional, 2007: Sentencia T-391/2007), así como la libertad de informar, que cobija tanto información sobre hechos como información sobre ideas y opiniones de todo tipo, a través de cualquier medio de expresión (Corte Constitucional, 2007: Sentencia T-391/2007).

La tercera liberta protegida por el art. 20 inc. $1^{\circ}$ de la Constitución Política de 1991 es la libertad de prensa, que se refiere no solo a los medios impresos sino a todos los medios masivos de comunicación (Corte Constitucional, 2007: Sentencia T-391/2007) y protege, en términos generales, la libertad de fundar medios masivos de comunicación, así como la libertad de estos medios de funcionar sin interferencias debidas, de forma tal que puedan cumplir sus funciones dentro de la sociedad democrática (Corte Constitucional, 2007: Sentencia T-391/2007). Asimismo, la Corte Constitucional ha sostenido que la libertad de prensa cuenta con unas características distintas a los otros dos derechos fundamentales (Corte Constitucional, 2007: Sentencia T-391/2007). 
B. Protección constitucional de la publicidad a través de la libertad de expresión

Si el art. 20 inc. $1^{\circ}$ de la Constitución Política de 1991 consagra tres Derechos fundamentales distintos, subordinados todos ellos a la libertad de expresión, es de cuestionarse cuál de ellos garantiza la creación de publicidad comercial. Esta identificación tiene especial importancia, pues cada uno de los derechos contenidos en el art. 20 inc. $1^{\circ}$ de la Constitución Política tiene un nivel de protección distinto (Corte Constitucional, 2000: Sentencia C-010/2000) y, por tanto, el nivel de intervención del Estado en cada uno de ellos también varía (Corte Constitucional, 2003: Sentencia C-650/2003). Así, mientras que la libertad de expresión en estricto sentido sólo permite la intervención en aquellos casos en los cuales se protejan otros derechos fundamentales, tales como la honra y el buen nombre, el derecho a la información encuentra límites no sólo en la protección de esos derechos fundamentales, sino también en la obligación de la búsqueda y transmisión de información veraz, por tanto, el Estado puede regular los contenidos transmitidos. El derecho a fundar medios masivos de comunicación, a su vez, encuentra sus límites no sólo en los derechos fundamentales de otras personas, sino también, en la obligación de creación de espacios democráticos, en el uso de bienes públicos como el espectro electromagnético y en el fomento de la cultura colombiana y, por tanto, la intervención estatal es mayor que en los otros dos derechos.

Para determinar en cuál de estos tres derechos puede ubicarse la publicidad comercial, es necesario saber cómo se ha entendido, desde el Derecho constitucional Colombiano, la publicidad comercial. Para la Corte Constitucional, la publicidad comercial se ha definido como un mecanismo de transmisión de mensajes persuasivos, que buscan dirigir las preferencias de los ciudadanos hacia determinado bien o servicio (Corte Constitucional, 2010: Sentencia C-830/2010). De esta definición se puede identificar, por una parte, dos elementos esenciales. El primero de estos elementos es el carácter económico de la publicidad comercial, es decir, que el objeto de la misma no es promover o alentar la participación y deliberación democráticas, sino la facilitación de transacciones económicas (Corte Constitucional, 2010: 
Sentencia C-830/2010). El segundo elemento es el carácter persuasivo de la publicidad comercial, es decir, que ésta no pretende simplemente informar a la comunidad -o a los consumidores en concreto- sobre la existencia de un producto, sino que pretende, a través de la exaltación de las bondades de un bien o servicio (Corte Constitucional, 2010: Sentencia C-830/2010), dirigir las preferencias de los consumidores hacia los mismos.

La definición de la Corte Constitucional permite, por otra parte, tener luces sobre el derecho fundamental que cobija la publicidad comercial. La publicidad comercial, por un lado, no es en sí misma el ejercicio del derecho de fundar medios masivos de comunicación, pues su objeto no es el de crear fuentes de información (televisiva, radial o impresa), sino el de transmitir, a través de los medios existentes, mensajes persuasivos sobre determinado bien o servicio. La publicidad comercial, por otro lado, no es reflejo de la libertad de expresión en estricto sentido, pues los mensajes transmitidos no son una simple idea $u$ opinión reflejo de una subjetividad no verificable (Corte Constitucional, 2003: Sentencia C-650/2003), sino que, por el contrario, son mensajes que transmiten una información que el consumidor, bien a la hora de comprar un producto o bien a la hora de consumirlo, puede corroborar. Por ejemplo, si la publicidad de un producto $X$ comunica que el mismo favorece al sistema digestivo por su bajo contenido en grasas, dicha afirmación podrá ser evaluada por el consumidor al momento de leer la información nutricional del producto. Al no estar cobijada la publicidad comercial por la libertad de expresión ni por el derecho a fundar medios masivos de comunicación, podría decirse que ella está protegida por el derecho a la información, especialmente por el derecho a transmitir información.

El objeto de la publicidad comercial es, en sí mismo, dar a conocer a la comunidad la existencia de un producto, el cual, cuenta con unas características propias que lo diferencian de otros y, por tanto, recomienda, a través de un lenguaje visual o auditivo de carácter persuasivo, que los consumidores se inclinen por él. La comunicación hecha por el publicitario no es una simple opinión respecto al producto, sino un acto de informar, pues da noticia de algo que aún no era conocido o que sólo era conocido por un círculo 
muy pequeño. En este sentido ha sostenido la Corte Constitucional que la publicidad comercial es información comercial, que deriva de la estrecha relación de estos mensajes con la actividad económica y de mercado, en la medida en que constituyen un incentivo para las transacciones comerciales (Corte Constitucional, 2000: Sentencia C-010/2000). Asimismo, la Corte Constitucional ha sostenido que la publicidad comercial, como discurso, es protegido por el derecho a la información, en tanto contiene un mensaje que desea divulgarse por el interesado en la venta del bien (Corte Constitucional, 2010: Sentencia C-830/2010).

Sin embargo, asumir que la publicidad comercial está garantizada en la libertad de información no es del todo preciso, pues, en realidad, la aplicación de este derecho fundamental en este caso es solamente parcial. Para la Corte Constitucional, la publicidad comercial se encuentra cobijada también por el derecho a la libertad de empresa e iniciativa privada, pues es evidente que una de las etapas esenciales para asegurar la comercialización es contar con la publicidad para que los consumidores opten por adquirir el producto (Corte Constitucional, 2010: Sentencia C-830/2010). Esta etapa, bajo un modelo de economía social de mercado, debe ser objeto de protección constitucional por parte del Estado, ya que ella hace parte del esfuerzo productivo y la ulterior concurrencia del agente y sus productos en el mercado (Corte Constitucional, 2010: Sentencia C-830/2010), y negarle o restringirle excesivamente la posibilidad de usar la publicidad al agente económico implicaría una afectación negativa para él en el ejercicio de la actividad económica y una negación a su derecho de libertad de empresa. La cuestión es, entonces, si la protección de la publicidad comercial a través del derecho de la libertad de empresa e iniciativa privada junto con la libertad de información implica una alteración en el nivel de protección.

\section{Límites constitucionales de la publicidad comercial}

Si bien la publicidad comercial está cobijada por la libertad de información, la misma no goza de los niveles de protección que otorga este derecho fundamental. Para la Corte Constitucional (2000: Sentencia C-010/2000), 
aunque la publicidad comercial, como discurso, se encuentra en el ámbito de aplicación de la libertad de información, la misma se encuentra también bajo el ámbito de aplicación de la libertad de empresa e iniciativa privada, la cual tiene unas restricciones mayores en virtud de la función social de la empresa y de la facultad de dirección económica del Estado.

El fundamento que ha permitido argumentar a la Corte Constitucional la existencia de un mayor límite y capacidad de restricción de la publicidad comercial pese a estar protegido por la libertad de información, se encuentra en la relación empresario-consumidor, el cual cuenta con una regulación de carácter constitucional y legal especial. Así, la Corte Constitucional ha sostenido que, en virtud del carácter poliédrico de los derechos de los consumidores, éstos no sólo tienen el derecho a acceder a los bienes y servicios ofrecidos por los agentes económicos en el mercado, sino también gozan de derechos de carácter sustancial -calidad bienes y servicios e información-, procesal -exigencia de garantías e indemnizaciones- y participativo -frente la acción pública- (Corte Constitucional, 2000: Sentencia C-1141/2000). Estos derechos, a su vez, constituyen un deber especial del Estado de garantizar que las relaciones con el consumidor no sean de carácter asimétrico (Corte Constitucional, 2000: Sentencia C-010/2000) y se impidan relaciones abusivas. Especialmente, en los derechos de carácter sustancial, el art. 78 inc. $1^{\circ}$ de la Constitución Política de Colombia establece que la ley regulará la calidad de bienes y servicios ofrecidos y prestados a la comunidad, así como la información que debe suministrársele al público en su comercialización, teniendo en cuenta que, la cantidad y calidad de datos sobre los productos que ofrezcan los comerciantes -a través del mensaje publicitario, son elementos críticos para el juicio de adecuación de las opciones de consumo (Corte Constitucional, 2000: Sentencia C-010/2000). Ello implica que la activad del empresario en cualquiera de sus etapas, especialmente en la publicidad comercial, se cumplan ciertos estándares, lo cuales garantizan que el consumidor, a la hora de elegir, está optando por una alternativa "informada" y por tanto, el empresario no podrá, en ningún momento, ocultar información u ofrecerla inadecuadamente, es decir, de forma ambigua, incompleta, o de otra forma semejante. 
Este ha sido el fundamento constitucional para que el Estado, a través del art. 14 del Decreto 3466 de 1982 y la ley 1480 de 2011, establezca normas de protección del consumidor contra publicidad engañosa. Especialmente, el art. 23 de la ley 1480 de 2011 consagra que los proveedores y productores deberán suministrar a los consumidores información, clara, veraz, suficiente, oportuna, verificable, precisa e idónea (...). Asimismo, el art. 30 inc. $1^{\circ}$ de la ley 1480 de 2011 establece la prohibición de la publicidad engañosa y, en caso de haberla transmitido, el anunciante será responsable por los perjuicios que cause la publicidad engañosa, conforme al art. 30 inc. $2^{\circ}$ de la ley 1480 de 2011.

Asimismo, la publicidad comercial encuentra otros límites que, si bien no están relacionados directamente con la cuestión de la publicidad engañosa, son de especial mención. Dichos límites son (Corte Constitucional, 2000: Sentencia C010/2010): a) la prohibición a personas de publicitar un servicio profesional sin tener el título de idoneidad respectivo; b) la prohibición de transmitir publicidad comercial por los servicios públicos de radiodifusión y; c) la prohibición de originarse propaganda comercial por los servicios de radiodifusión educativa.

\section{La cuestión constitucional de responsabilidad de los medios de comunicación por publicidad engañosa}

Si bien la publicidad comercial se encuentra protegida por el art. 20 inc. $1^{\circ}$ de la Constitución Política de Colombia, su aplicación está dirigida solamente a quien crea $\mathrm{o}$ transmite dicha publicidad, es decir, protege solamente al empresario quien, en ejercicio de su actividad económica, busca nuevos clientes mediante la emisión de mensajes persuasivos y, por tanto, las restricciones constitucionalmente legítimas se encuentran destinadas solamente a él. Por ello, el art. 23 de la Ley 1480 de 2011 consagró la obligación de brindar información veraz sólo al productor y al proveedor, mientras que el art. 30 inc. $2^{\circ}$ de la ley 1480 de 2011 establece la responsabilidad del anunciante por los daños que cause la publicidad engañosa. Asimismo, la jurisprudencia de la Corte Constitucional en materia de 
la publicidad comercial ha sostenido la responsabilidad que tiene el empresario a la hora de transmitir mensajes persuasivos, con miras a cambiar el comportamiento del consumidor (Corte Constitucional, 2010: Sentencia C830/2010).

Por tanto, es de cuestionarse si la nueva medida, consagrada en el art. 30 inc. $2^{\circ}$ de la ley 1480 de 2011 y que consagra responsabilidad de los medios de comunicación por difusión de publicidad engañosa, constituye una medida constitucionalmente adecuada o si, por el contrato, es desproporcionada, al atentar contra algún derecho fundamental. Esta pregunta es de especial interés, pues los medios de comunicación no participan, prácticamente, de la relación empresario-consumidor, sino que cumplen una función distinta. La función del medio de comunicación, cualquiera que sea su tipo -radial, televisivo o impreso-, no es la de diseñar publicidad o mensajes persuasivos para convencer o cambiar la inclinación del consumidor hacia ciertos productos. La función del medio de comunicación es, en realidad, la de servir como soporte para la difusión masiva de información, traducida en contenidos de carácter no sólo comercial, sino cultural, política, social y lúdica (véase Corte Constitucional, 2007: Sentencia T-391/2007). Al no tener como función la creación de publicidad comercial es de cuestionarse si el legislador o el ejecutivo, en uso de sus facultades constitucionales, puede imponer sanciones por la transmisión de publicidad engañosa, bien sea que la transmisión se haya dado por una actuación dolosa o culposa, y afectar así el derecho fundamental de la libertad de fundar medios masivos de comunicación.

Para poder determinar si los medios de comunicación son responsables por emisión de publicidad engañosa, es necesario establecer si, en virtud de su función o papel social, los mismos deben cumplir con un deber de control de contenidos, pues, si los medios de comunicación cumplen una mera función de ser soporte de transmisión sin deber alguno de controlar los contenidos, la imposición de una sanción por transmisión de publicidad engañosa sería desproporcionada. En cambio, si los medios de comunicación no sólo tienen como función transmitir sino controlar lo transmitidos, sería posible imponer sanciones por el no cumplimiento de controlar los mensajes presentados por 
empresarios. Pero, en caso de ser afirmativo, es necesario cuestionarse también por los estándares de control que debe cumplir un medio de comunicación.

Una posible respuesta podría consistir en la no existencia de un control de contenidos por parte del medio de comunicación, pues las normas que protegen a la comunidad, especialmente a los consumidores, tienen como destinatario el productor, proveedor o anunciante, son ellos quienes, bajo la obligación de brindar información clara y veraz de su producto conforme al art. 14 del decreto 3466 de 1982 y del art. 23 de la ley 1480 de 2011, deben revisar cuáles son los parámetros que debe cumplir una propaganda comercial o la publicidad a la hora de transmitirla. Por ello, el productor, proveedor o anunciante debe cerciorarse sobre el cumplimiento de los requisitos establecidos en el art. 14 del decreto 3466 de 1982, a saber, que la información transmitida corresponda con la realidad del producto, que se cumplan con las licencias o registros necesarios y que las normas técnicas hayan sido acatadas. Asimismo, el art. 24 num. 1 de la ley 1480 de 2011 establece que el productor deberá ofrecer información sobre el correcto uso o consumo, la cantidad, peso o volumen, la fecha de vencimiento -en caso de ser aplicable- y las especificaciones sobre el bien o servicio, mientras que el proveedor deberá informar, conforme al art. 24 num 2 de la ley 1480 de 2011, sobre las garantías que asisten a los consumidores y el precio, así como verificar las informaciones dadas por el productor.

Por otra parte, los medios masivos de comunicación no son órganos de control especializados. Asumir que un medio de comunicación puede controlar la información sobre productos, implicaría que aquel cuenta, dentro de su estructura, con un equipo especializado que conoce las condiciones que debe cumplir cada producto, así como las normas técnicas que deben cumplirse en casos particulares, tales como el caso de farmacéuticos u otros. Ello sería, técnica y financieramente, imposible para cualquier operador de radio y televisión así como para la prensa escrita, pues demandaría una planta de personal compleja y costosa. Además, es necesario tener en cuenta, que las funciones de control de calidad y de implementación de normas técnicas 
corresponden a entidades estatales que tienen, dentro de sus funciones, controlar los bienes y servicios que son ofrecidos en el mercado. Por ejemplo, la Superintendencia de Industria y Comercio, mediante resolución 172 de 2012 estableció el reglamento técnico aplicable a pilas Zinc-Carbón y alcalinas que se importen o fabriquen para su comercialización en Colombia, así como el Instituto Nacional de Metrología expide normas técnicas en materia de medición, conforme a estándares internacionales.

Sin embargo, desde la perspectiva constitucional, eximir de responsabilidad a los medios de comunicación por transmisión de publicidad engañosa no es justificable. Los medios de comunicación, al ser el soporte o facilitador de la información, tiene algunas responsabilidades, especialmente en materia de objetividad. De acuerdo a la Corte Constitucional, quien emite la información, dada la cobertura que tiene su labor y el impacto de la misma en la opinión pública, está en la obligación de hacerlo de manera objetiva, ciñéndose a los hechos, orientado a la opinión pública y de ser el caso alertándola (Corte Constitucional, 1997: Sentencia C-350/1997). Asimismo, la Corte Constitucional prohibió, partiendo del deber de objetividad, manipular la información para sus propias convicciones o hacerla útil a sus intereses, pues con ello no sólo vulneraría los derechos fundamentales de terceros, sino que atentaría contra los fundamentos mismos del Estado (Corte Constitucional, 1997: Sentencia C350/1997). Dentro de la prohibición de manipulación de información, la Corte Constitucional ha identificado distintas clases, entre ellas la pseudo-información o falsa información, que puede provenir del medio de comunicación, de quien entrega la información o del Estado, y que vulnera no sólo al individuo, quien aspira a encontrar en los medios de comunicación un instrumento mediático, que lo ponga en contacto con mundos diversos a partir de los cuales puede ejercer su autonomía, sino también a la sociedad entera que ve afectada su capacidad de participación y decisión (Corte Constitucional, 1997: Sentencia C350/1997).

Un contra-argumento que podría fundamentar que, en el caso de publicidad engañosa, los medios de comunicación no son responsables, sería que los mismos no manipulan la información ni reciben beneficio, pues éste sólo se 
presentaría al productor, proveedor, o anunciante, quienes lograrían, mediante la transmisión de información manipulada, que el consumidor cambiase su inclinación hacia el producto publicitado. Sin embargo, es necesario tener presente que, por la publicidad comercial emitida por los medios de comunicación, si bien no se tiene un beneficio por la persuasión del consumidor, si existe un beneficio indirecto, a saber, se recibe un beneficio por el otorgamiento del espacio publicitario al productor, proveedor o anunciante, que se traduce, generalmente, en dinero. Asimismo, afirmar que los medio de comunicación no manipulan la información y, por ello, no son responsables, es errada, pues, como se mencionó, la Corte Constitucional sostuvo que, en virtud de la objetividad, los medios de comunicación deben velar por los contenidos (Corte Constitucional, 1997: Sentencia C-350/1997).

Por otro lado, la legislación colombiana, concretando el deber de objetividad de los medios de comunicación y la función social de los mismos, ha consagrado normas de control de contenidos para los medios de comunicación. Así, el art. 11 inc. $1^{\circ}$ y $2^{\circ}$ de la ley 74 de 1966 estableció que ni por los servicios públicos de radiodifusión ni escuelas radiofónicas o de experimentación científica que estén exentas de funcionamiento o que reciban subvención del Estado, podrá originarse propaganda comercial; mientras que el art. 13 inc. $3^{\circ}$ de la ley 74 de 1966 se establece que el Estado reglamentará la propaganda de productos farmacéuticos, higiénicos, alimenticios y similares, pudiendo prohibir aquella que a su juicio atente contra la salud o los intereses del consumidor, norma que debe interpretarse a la luz de la legislación del consumidor, la cual determina que todo producto debe cumplir con requerimiento de calidad. Asimismo, el art. 29 inc. $2^{\circ}$ de la ley 182 de 1995 establece que los contenidos de publicidad podrán ser clasificados y regulados por la Comisión Nacional de Televisión, con miras a promover su calidad, garantizar el cumplimiento de los fines y principios que rigen el servicio público de televisión, protegen a la familia, a los grupos vulnerables de la población, en especial de los niños y jóvenes, para garantizar su desarrollo armónico e integral. En este sentido, controlar y establecer estándares sobre los contenidos que deben permitir los medios de comunicación, no es un acto desproporcionado que afecta los derechos 
fundamentales de los operadores de radiodifusión o televisión, así como de la prensa escrita.

Un último aspecto por resolver consiste en saber cuáles son los controles que debe realizar un medio de comunicación para poder permitir la emisión de publicidad, pues, si bien el mismo es responsable por un control de emisión de contenidos, también es cierto que no es un organismo de control, sino un escenario de transmisión. En este sentido, podría afirmarse, inicialmente, que los controles que debe realizar un medio radiofónico, televisivo o de prensa escrita, no deben corresponder a los realizados por órganos especializados, tales como el Instituto Nacional de Metrología o los peritos de la Superintendencia de Industria y Comercio. Sin embargo, los medios de comunicación cuentan con herramientas que, en ningún momento, son excesivas. La primera de ellas es la ley 1480 de 2011 o nuevo Estatuto del Consumidor el cual, de forma, sencilla, establece cuáles son las informaciones que debe brindar el productor, proveedor o anunciante, a saber, las calidades del producto, fechas de vencimiento -si proceden- y sus medidas, así como las indicaciones o contraindicaciones del producto. La segunda herramienta es el producto mismo el cual, de acuerdo con la legislación vigente, debe contar, bien sea en su empaque o en el producto mismo, con información sobre el contenido, calidades, fechas y contraindicaciones, las cuales pueden ser cotejadas con la publicidad que desea transmitir el productor, proveedor 0 anunciante. La tercera herramienta es, en caso de productos específicos, el registro o licencia, la cual puede ser solicitada por el medio de comunicación antes de ser aceptada la publicidad a ser emitida.

Por tanto, la responsabilidad del medio de comunicación procedería sólo en aquellos casos en los cuales el mismo no atendió las indicaciones establecidas por la ley, sin necesidad de realizar controles propios de organismos especializados y, en este sentido, el art. 30 inc. $2^{\circ}$ de la ley 1480 de 2011 no es una violación al derecho fundamental de la libertad de fundar medios masivos de comunicación, sino una reiteración de la función social que cumplen los mismos. 


\section{Síntesis}

La publicidad comercial, desde el derecho constitucional económico, es expresión del derecho fundamental de información, especialmente a transmitir información, y del derecho fundamental de libertad de empresa y de iniciativa privada, pues a través de él el productor o proveedor promocionan su producto y buscan clientes. Asimismo, la publicidad comercial ha sido entendida, desde la jurisprudencia constitucional, un mecanismo de transmisión de mensajes persuasivos, que buscan dirigir las preferencias de los ciudadanos hacia determinado bien o servicio. Sin embargo, no toda publicidad es legítima, pues existe un límite constitucional consagrado en los derechos del consumidor, especialmente en el derecho a recibir información veraz y clara, que corresponda a la realidad del producto ofrecido.

Este límite ha legitimado al legislador y al ejecutivo para expedir normas e imponer sanciones en aquellos casos en los cuales, el productor o proveedor promocionan un producto a través de una publicidad no coherente con la realidad. Así, el antiguo estatuto del consumidor, el decreto 3466 de 1982, consagró la prohibición de utilizar publicidad que no correspondiese con la realidad del producto, induciendo o pudiendo inducir a error o engaño, figura que se conoció inicialmente por la Superintendencia de Industria y Comercio, como información. Posteriormente, el nuevo estatuto del consumidor, la ley 1480 de 2011, consagró la figura de la publicidad engañosa, entendida como entendida como aquella cuyo mensaje no corresponda a la realidad o sea insuficiente, de manera que induzca o pueda inducir a error, engaño o confusión, e impuso sanciones a los anunciantes por la transmisión de publicidad engañosa.

Lo interesante de esta nueva ley es que, además de responsabilizar al anunciante, la misma le impone una responsabilidad solidaria a los medios de comunicación por difundir, dolosa o culposamente, publicidad engañosa. Esta norma, si bien novedosa, pareciese en principio atentatoria del derecho fundamental de la libertad de fundar medios masivos de comunicación, pues ella le impone, aparentemente, la carga al medio de comunicación de operar 
como organismo de control de calidad de los productos. Asimismo, le impone una aparente sanción al medio de comunicación por una publicidad que no ha tenido origen en él, es decir, lo estaría sancionando por un acto no cometido por él. Sin embargo, la jurisprudencia de la Corte Constitucional ha sostenido que los medios de comunicación como espacios democráticos y de transmisión de información, deben cumplir con un deber de objetividad, el cual prohíbe, entre otras, la pseudo información o información falsa, la cual afecta el criterio del consumidor. Asimismo, la historia legislativa ha demostrado que ese deber de objetividad ha estado presente en los medios de comunicación a través de los controles de contenidos, consagrados en las normas de radiodifusión y de televisión. Por otra parte, no existe una desproporcionalidad constitucional, pues el deber del medio de comunicación consiste, realmente, en cotejar la normativa en materia de publicidad, el producto y la publicidad a ser emitida.

\section{Referencias}

CÁRDENAS, Juan (2010), la garantía de la libertad de expresión, en RODRÍGUEZ V., Miguel; VILLANUEVA, Ernesto (2010), compromiso con la libertad de expresión: análisis y alcances, México.

COHEN, Dorothy (1980), publicidad comercial, 3ª edición, México.

CONGRESO DE LA REPÚBLICA DE COLOMBIA (2010), proyecto de ley 089 de 2010 -Cámara-, por medio del cual se expide el Estatuto del Consumidor, se crea una contribución para la defensa del mismo y dictan otras disposiciones, en Gaceta del Congreso, No. 626 de 2010, Colombia.

Corte Constitucional (2010), Sentencia de Constitucionalidad C-830 de 2010.

(2000), Sentencia de Constitucionalidad C-010 de 2000.

(1997), Sentencia de Constitucionalidad C-350 de 1997.

(2007), Sentencia de Tutela T-391 de 2007.

(2003), Sentencia de Constitucionalidad C-650 de 2003.

- (2001), Sentencia de Constitucionalidad C-1259 de 2001.

- (2010), Sentencia de Tutela T-161 de 2010.

- (2004), Sentencia de Tutela T-787 de 2004.

(1998), Sentencia de Unificación SU-182 de 1998.

CORTE SUPREMA DE JUSTICIA (2011), Sala de Casación Civil, Sentencia del 1 de noviembre de 2011 (029201/2011). 
- (2001), Sala de Casación Civil, Sentencia del 13 de diciembre de 2001 (6775/2001).

GARCÍA-UCEDA, Mariola (2008), las claves de la publicidad, 6ª edición, Madrid, España.

ISLER S., Erika M. (2010), aproximación a la publicidad engañosa, desde la perspectiva de la competencia desleal y la protección al consumidor, en Ars Boni et Aequi, No. 6, Chile.

PEREZ E., Jacobo (2004), Derecho constitucional colombiano, $7^{a}$ edición, Bogotá, Colombia.

RODRÍGUEZ C., Juan Carlos (2004), la publicidad como herramienta de las distintas modalidades de comunicación persuasiva, en Global Media Journal en $\begin{array}{llllll}\text { español, } & \text { Vol. } & 1 & \text { No. } & 1, & 2004,\end{array}$ http://gmje.mty.itesm.mx/articulos1/pdf/centeno.pdf.

SUÁRES V., Juan C.; PÉREZ C., Mª Ángeles (2001), la publicidad al desnudo: análisis social del discurso publicitario, $1^{2}$ e edición, España.

SCRETI, Francesco (2011/2012), publicidad y propaganda: terminología, ideología, ingenuidad, en Razón y Palabra, No. 78, en www.razonypalabra.org.mx.

YOUNES, Diego (2011), Derecho constitucional colombiano, $11^{\text {ạ }}$ edición, Bogotá, Colombia. 